\title{
A Proposal for FDA Oversight of Tear Gas
}

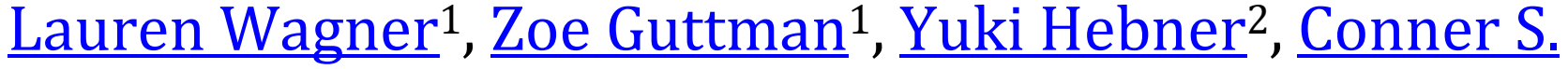 Philson $^{3}$}

1University of California, Los Angeles, Neuroscience Interdepartmental Program, Los Angeles, CA

2University of California, Los Angeles, Molecular Biology Interdepartmental Program, Los Angeles, CA

${ }^{3}$ University of California, Los Angeles, Department of Ecology and Evolutionary Biology, Los Angeles, CA https://doi.org/10.38126/ISPG180115

Corresponding Author: lwag@ucla.edu

Keywords: tear gas; crowd control; chemical weapons; public health; protests; regulation; CS gas

Executive Summary: Tear gas is designated a chemical weapon by multiple treaties that prohibit its use in war. However, despite mounting reports suggesting that tear gas may endanger targets beyond transient discomfort, its domestic use as a crowd control mechanism has not been adequately studied, nor is its use regulated by any United States government agency. Without comprehensive and demographically-representative epidemiological studies, the continued use of tear gas on civilian protesters poses an unknown and potentially severe threat to public safety. Chemical substances employed on civilians for a desired effect are more akin to drugs than to weapons. We, therefore, propose that legislation be introduced to place tear gas under the regulatory purview of the Food and Drug Administration (FDA) in order to understand its effects on the health of all members of the public and to better regulate its deployment.

\section{Statement of issue}

Despite being internationally outlawed for war, the use of tear gas against civilian protesters continues unchecked by any United States federal agency. While mounting reports suggest that tear gas exposure produces health consequences beyond transient noxious effects, this evidence is largely anecdotal due to a scarcity of formal research and a lack of federal regulation. American law enforcement agencies frequently oversee crowd control when citizens exercise their right to peaceably assemble, as is guaranteed by the First Amendment of the United States Constitution. Crowd control tactics can be limited to preventative measures, such as designating protest areas and curfews, but can also include the use of "less-lethal" weapons that promote crowd dispersal by inflicting temporary pain or discomfort (Gupta 2015). Such methods, including the use of tear gas, are typically considered last resorts but, when used, are rationalized as a means to de-escalate what would otherwise become a more violent situation.

Initially designed for chemical warfare, tear gas was widely used in World War I before entering municipal police departments (Feigenbaum 2014). After World
War I, chemical warfare - including the use of tear gas - was internationally banned by signatories of the Geneva Protocol of 1925 (Geneva Protocol 1925). The later Chemical Weapons Convention introduced further restrictions on use and stockpiling (Geneva 1992). However, in both instances, the United States reserved the right to use and stockpile tear gas for domestic crowd control purposes. Despite its name, tear gas is a potent chemical irritant that targets the respiratory tract, gastrointestinal system, eyes, and skin. Exposure causes acute nausea, vomiting, respiratory distress, burns, and dermatitis (CDC 2018; Anderson et al. 1996; Rothenberg et al. 2016). Tear gas has also been associated with chronic illness and injuries, including lung injury (Rothenberg et al. 2016), blindness (CDC 2018; Haar et al. 2017a), chemical burns (CDC 2018), cutaneous conditions (Watson and Rycroft 2005), and even death (Haar et al. 2017a; Salo 2020; Brown 2014). These reported health hazards are especially alarming in light of studies associating the molecular receptors that tear gas targets with common health conditions such as asthma (Hox et al. 2013), diabetes (Koivisto et al. 2012), arrhythmia, and hypertension (Wang et al. 2019). The incomplete understanding of the 
physiological consequences of tear gas exposure was especially concerning in 2020, given the high rates of public exposure to tear gas during the Black Lives Matter movement and the coincident COVID-19 pandemic. Over 1,000 public health professionals, infectious diseases experts, and community stakeholders collectively voiced opposition to tear gas use in an open letter, citing concerns that both tear gas and SARS-CoV-2 target the respiratory system (Public health professionals, infectious diseases professionals, and community stakeholders 2020).

The lack of scientific evidence that tear gas is safe for the public, despite over a century of use, can likely be attributed to the fact that no United States government agency directly regulates tear gas. The 1972 Federal Advisory Committee Act (FACA) designated the creation of the National Advisory Committee for Acute Exposure Guideline Levels for Hazardous Substances (NAC/AEGL) to develop AEGLs for high-priority, toxic chemicals such as CS gas (a commonly deployed tear gas). The resulting 2014 report was unable to discern a minimum concentration of CS gas at which there are no irreversible health effects for the general public. In addition, the report indicated no agency responsible for regulation or oversight (National Research Council 2014), demonstrating the limited nature of US federal research and regulation concerning tear gas.

Agencies overseeing commercial chemical substances include the Environmental Protection Agency (EPA), Occupational Safety and Health Administration (OSHA), and Food and Drug Administration (FDA). The scope of substances and markets regulated by these entities is delimited by the legislation that established these agencies and subsequent legislation expanding their purview. However, tear gas is not under the ambit of any of these regulatory agencies. Without a federal regulatory mechanism overseeing tear gas manufacture and deployment, its continued use on the public may pose unknown health threats. This lack of regulation starkly contrasts with the approval process mandated for other widely-dispersed chemical substances such as medicines, cosmetics, and pesticides.

\section{Epidemiological studies of tear gas}

Long-term, demographically representative toxicological studies on the effects of tear gas are sorely lacking in the literature (Rothenberg et al. 2016, Fraunfelder 2000, Hu et al. 1989). The majority of epidemiological studies on tear gas have been conducted in United States military training populations (Haar et al. 2017a) and report a substantially greater risk $(2.4 \mathrm{x})$ of acute respiratory illness diagnosis following tear gas exposure (Hout et al. 2014a). Moreover, epidemiological studies have yet to meaningfully include vulnerable populations like women, children, the elderly, and those with underlying health conditions (Rothenberg et al. 2016; Hout et al. 2014a, b; Wetsman 2020). Reported reproductive consequences, such as menstrual dysregulation and miscarriages (Wetsman 2020; Hayman 2011; Sollom and Atkinson 2020), underscore this urgent need for broad and diverse representation in future tear gas research. Twenty years after a report on tear gas from the British Department of Health found no data relating to reproductive toxicity (Department of Health 1999), the nonprofit Planned Parenthood has independently begun the first large-scale survey of tear gas and reproductive health (Planned Parenthood North Central States 2020). The limited scope of existing research significantly hinders the generalizability of commonly accepted safety claims and renders the health effects of tear gas on sensitive populations under-assessed.

\section{Mechanistic studies of tear gas}

The term "tear gas" most commonly refers to the aerosolized lachrymator agents 2chlorobenzalmalonitrile (CS) and oleoresin capsicum (OC). The characteristic noxious effects of tear gas exposure are induced when CS and OC bind to receptors (Transient Receptor Potential ion channels TRPV1 and TRPA1) expressed in pain-sensing nerves throughout the body (Lindsay et al. 2015; Brone et al. 2008; Caterina et al. 1997). Studies of these receptors have reported that they are chronically activated in respiratory, dermal, cardiovascular, and metabolic systems in animal models of asthma, dermatitis, arrhythmias, and diabetes, respectively (Hox et al. 2013; Liu et al. 2013; Hazari et al. 2011; Koivisto et al. 2012). Given that tear gas targets the same receptors that are implicated in several underlying conditions, tear gas exposure should not be assumed safe for the general public without further analysis (Rothenberg 
2016). Additionally, the American Lung Association and the CDC state that individuals with pre-existing respiratory conditions have a higher risk of developing severe (potentially fatal) respiratory symptoms in response to tear gas (American Lung Association 2020), and that prolonged exposure can cause respiratory issues such as asthma (CDC, 2018). However, these statements do not cite epidemiological studies - a substantial shortcoming that underscores the persistent lack of data pertaining to long-term health implications of tear gas use and the potential role of aforementioned medical conditions. It is also important to note that because airborne chemical agents are indiscriminate, tear gas deployment can impact bystanders and nearby residents of any age, demographic, or medical background (Hu et al. 1989, Selsky 2020; Mccrystal 2020; Graham 2020). For example, tear gas has reportedly exacerbated the respiratory conditions of untargeted hospital patients (Hu et al. 1989).

\section{Existing regulations and stakeholders' views}

The authors found no current tear gas bans in any nation, although outdoor use was banned in Sweden until 2012 (Sveriges Radio 2012). A recent report by the Associated Press also outlines their unsuccessful search to locate any US federal or state oversight into tear gas manufacturing or use (Selsky 2020). Given that the United States is the primary manufacturer and exporter of tear gas to governments around the world, American regulations on tear gas will likely have global implications (Borrell 2011; Adams 2019). Domestically, enhanced regulations would likely benefit tear gas production workers, who have reported health complications from exposure to toxic ingredients and byproducts (Adams 2019; Miranda 2020). The majority of the American public (70\%), does not support using tear gas against peaceful protesters (Ipsos 2020). Without comprehensive safety considerations for the general public, the continued use of tear gas may discourage vulnerable demographics, such as those with asthma, from exercising their First Amendment right to assembly-potentially amounting to health-based discrimination.

\section{Policy recommendation}

We propose that federal legislation place tear gas (CS and OC) under the purview of the FDA as a mechanism to formally address whether tear gas is safe for public use, ensuring that scientific rigor and multidisciplinary efforts are employed to determine whether tear gas poses a substantial threat to the public. While past calls for moratoria and increased research in the United States (Hu et al. 1989; Public health professionals, infectious diseases professionals, and community stakeholders 2020; American Thoracic Society 2020; Wilkinson 2020) have gone largely unaddressed, the imposition of FDA oversight for tear gas use would serve as a concrete mechanism to protect the public from this underassessed risk. The FDA is the appropriate regulatory body for such oversight, as chemical compounds employed on civilians to achieve a desired effect (less-lethal crowd dispersal) should be regulated more similarly to drugs than to weapons (Himsworth 1971).

While FDA evaluation does not require a national pause on tear gas use (such a pause did not occur when tobacco was placed under FDA purview), consistency with the typical drug approval process (FDA 2019) would encourage one. We recommend that a national moratorium accompany the FDA's period of review in order to halt risk potential. Moreover, FDA investigations must be representative of currently under-studied demographics and those with potentially complicating comorbidities. The vast majority of studies that report no significant health concern upon tear gas exposure were conducted in small sample sizes (Beswick et al. 1972) and excluded children, women, the elderly (Hout et al. 2014a), and subjects affected by pre-existing conditions (Rothenberg 2016) (e.g., those with a history of chronic respiratory conditions (Hu et al. 1989)). This gap in knowledge perpetuates a limited understanding of the health risks of tear gas.

Because of the substantial potential for tear gas to be seriously or fatally misused (Haar et al. 2017a; Lai et al. 2020) by being aimed at individuals (Lai et al. 2020; Wani et al. 2011; Gabbatt 2011; Schuhmacher 2020) or used in an enclosed space (Brown 2014; Breakell and Bodiwala 1998), FDA regulation must also include oversight and guidance on deployment during crowd control operations. Such standards should include federally outlawing the shooting of gas canisters directly at individuals, outlawing the use of CS and OC gas within a confined space, and establishing nationally-standardized training requirements for deployment. 
The United States Congress may place the tear gas industry under the FDA's regulatory purview by passing a federal statute. Similar legislation (Family Smoking Prevention and Tobacco Control Act 2009) was enacted as recently as 2009 to allow the FDA to regulate the tobacco industry, leading to the creation of the Center for Tobacco Products within the FDA.

\section{i. Advantages}

- Placing tear gas under the purview of the FDA would provide a mechanism for comprehensive research to identify health risks for many demographics, including those with pre-existing conditions. This would address a critical gap in public health and chemical regulation.

- FDA oversight would establish regulatory standards for proper deployment and consequences for misuse. A 2017 lawsuit recorded 590 projectiles, including tear gas canisters, shot directly at protesters (Dinzeo 2018), some of whom required hospitalization. Blunt-force trauma from improper canister deployment has caused broken cartilage and bones (Schumacher 2020), ocular injuries (Sharma et al. 2014), including blindness (Lai et al. 2020, Schumacher 2020), vascular injury (Wani et al. 2011), and traumatic brain injury (Gabbatt 2011, Schumacher 2020). Requiring safe deployment by establishing uniform standards and enforcing consequences for misuse would reduce such incidents, demonstrating an emphasis on civilian safety.

- An emphasis on the health and safety of all demographics would enhance public trust in science and law enforcement. A concerted effort by legislators and scientists to prioritize public health and police accountability will help rebuild trust amid a turbid political climate and an ongoing public health crisis.

\section{ii. Disadvantages}

- Opposition by law enforcement and manufacturers is expected. The FDA would have the authority to regulate the manufacturing, sale, and use of tear gas according to results of the approval process, and the implementation of such regulation would likely meet resistance. The imposition of federal regulation could additionally be seen as a step towards a tear gas ban, which law enforcement has historically opposed.

- Research efforts will require additional federal funding. The proposed Congressional legislation may address this by including a section to allocate funding for FDA-associated laboratories and for federal grants to be awarded to academic laboratories wishing to participate in this research.

- The use of alternative violent crowd control tactics (i.e., rubber bullets, flash bangs) may increase if an FDA investigation leads to a ban on tear gas use. Such crowd control devices pose their own issues to public health and safety (see Haar et al. 2017b, Mutasa 2020) and must not wholly replace tear gas. De-escalation and protest planning should be prioritized above reactive violence, but, when necessary, potential nonviolent riot mitigation devices could include slow-release smoke grenades.

\section{Conclusion}

Instating FDA oversight for tear gas manufacturing and use will help renew public trust in science and law enforcement by prioritizing the safety of citizens exercising their First Amendment rights. Permitting tear gas use to proceed unchecked by a federal regulatory mechanism allows civilian protesters, especially those from sensitive demographics, to be exposed to potential unknown health risks. Therefore, the continued use of tear gas by law enforcement must be contingent on comprehensive assessments of its threat to all members of the public, standards for proper deployment, and mechanisms ensuring accountability for improper deployment. 


\section{References}

Adams, Rosalind. 2019. "Made In America: For $\$ 9.50 \mathrm{An}$ Hour, They Brew Tear Gas For Hong Kong." BuzzFeed News, September 5. https://www.buzzfeednews.com/article/rosalin dadams/tear-gas-hong-kong-made-in-usa.

American Lung Association. "Tear Gas." American Lung Association, June 6, 2020. https://emergency.cdc.gov/agent/riotcontrol/fa ctsheet.asp.

American Thoracic Society. 2020. "Tear Gas Use During COVID-19 Pandemic Irresponsible; Moratorium Needed, Says American Thoracic Society." American Thoracic Society, June 11. https://www.thoracic.org/about/newsroom/pre ss-releases/journal/2020/tear-gas-use-duringcovid-19-pandemic-irresponsible-moratoriumneeded,-says-american-thoracic-society.php.

Anderson, PJ, G Lau, W Taylor, J Critchley. 1996. "Acute effects of the potent lacrimator ochlorobenzylidene malononitrile (CS) tear gas." Human \& Experimental Toxicology 15(6): 461-465. https://doi.org/10.1177/096032719601500601.

Beswick, F W, P Holland, K H Kemp. 1972. "Acute effects of exposure to orthochlorobenzylidene malononitrile (CS) and the development of tolerance." British Journal of Industrial Medicine 29 (3): 298-306. https://doi.org/10.1136/oem.29.3.298.

Borrell, Brendan. 2014. "The Truth Behind Tear Gas: Most of It Is Made in America." TakePart, February 26. http://www.takepart.com/feature/2014/02/26/ how-us-sells-tear-gas-to-oppressive-regimes.

Breakell, A, GG Bodiwala. 1998. "CS gas exposure in a crowded night club: the consequences for an accident and emergency department." Journal of Accident \& Emergency Medicine 15 (1): 56. https://dx.doi.org/10.1136\%2Femj.15.1.56.

Brone, Bert, Pieter J Peeters, Roger Marrannes, Marc Merken, Ronny Nuydens, Theo Meert, Harrie J M Gijsen. 2008. "Tear gasses CN, CR, and CS are potent activators of the human TRPA1 receptor." Toxicology and Applied Pharmacology 231 (2): 150-156. https://doi.org/10.1016/j.taap.2008.04.005.

Brown, Julie K. 2014. "After Florida inmate's lethal gassing, claims of cover-up." Miami Herald, August 30. https://www.miamiherald.com/news/politicsgovernment/article1985286.html.

Caterina, Michael J, Mark A Schumacher, Makoto Tominaga, Tobias A Rosen, Jon D Levine, David Julius. 1997. "The capsaicin receptor: a heatactivated ion channel in the pain pathway." Nature 389 (6653): 816-824. https://doi.org/10.1038/39807.
CDC. "Facts About Riot Control Agents Interim Document." Centers for Disease Control and Prevention. US Department of Health and Human Services, April 4 ,

2018 https://emergency.cdc.gov/agent/riotcontrol/fa ctsheet.asp.

Department of Health. 1999. "1999 Annual Report of the Committees on Toxicity Mutagenicity Carcinogenicity of Chemicals in Food, Consumer Products and the Environment." Crown Copyright. https://cot.food.gov.uk/sites/default/files/cot/c otcomcoc1999.pdf.

Dinzeo, Maria. 2018. "Protesters Sue Phoenix Over Police Actions at Trump Rally." Courthouse News Service, September https://www.courthousenews.com/protesterssue-phoenix-over-police-actions-at-trump-rally/.

Family Smoking Prevention and Tobacco Control Act, Pub. L. No. 111-31 (2009). FDA. "Development \& Approval Process | Drugs." U.S. Food \& Drug Administration, October 28, 2019. https://www.fda.gov/drugs/developmentapproval-process-drugs.

Feigenbaum, Anna. 2014. "100 Years of Tear Gas." The Atlantic, Aug 16. https://www.theatlantic.com/international/arch ive/2014/08/100-years-of-tear-gas/378632/.

Fraunfelder F T. 2000. "Is CS gas dangerous? Current evidence suggests not but unanswered questions remain." BMJ (Clinical research ed.), 320 (7233), 458-459.

https://doi.org/10.1136/bmi.320.7233.458.

Gabbatt, Adam. 2011. "Occupy Oakland: Iraq war veteran in critical condition after police clashes." The Guardian, October 26. https://www.theguardian.com/world/2011/oct/ 26/occupy-oakland-veteran-critical-condition.

Geneva Protocol (Conference for the Supervision of the International Trade in Arms and Ammunition and in Implements of War), Geneva, 1925. "Protocol for the prohibition of the use in war of asphyxiating, poisonous or other gases, and of bacteriological methods of warfare." Signed at Geneva, on June 17, 1925.https://unoda-web.s3accelerate.amazonaws.com/wpcontent/uploads/assets/WMD/Bio/pdf/Status P rotocol.pdf.

Geneva, 1992. "Convention on the Prohibition of the Development, Production, Stockpiling and Use of Chemical Weapons and on their Destruction". United Nations Treaty Collection. https://treaties.un.org/Pages/ViewDetails.aspx? src=TREATY\&mtdsg no $=X X V I-$ 3\&chapter=26\&lang=en. 
Graham, Nathalie. 2020. "Seattle Residents Got Tear Gassed in Their Own Apartments." The Stranger, Jun 4. https://www.thestranger.com/slog/2020/06/04 $\not 43840246 /$ seattle-residents-got-tear-gassed-intheir-own-apartments.

Gupta, Ramesh C. Handbook of Toxicology of Chemical Warfare Agents. Academic Press, 2015.

Haar, Rohini J, Vincent Iacopino, Nikhil Ranadive, Sheri D Weiser, Madhavi Dandu. 2017. "Health impacts of chemical irritants used for crowd control: a systematic review of the injuries and deaths caused by tear gas and pepper spray." BMC Public $\begin{array}{llll}\text { Health } & 17 & \text { (1): } & \end{array}$ https://doi.org/10.1186/s12889-017-4814-6.

Haar, Rohini J, Vincent Iacopino, Nikhil Ranadive, Madhavi Dandu, Sheri D Weiser. 2017. "Death, injury and disability from kinetic impact projectiles in crowd-control settings: a Systematic review." BMJ open 7 (12). http://dx.doi.org/10.1136/bmjopen2017-018154.

Hayman, Mari. 2011. "Chile suspends use of tear gas amid concerns over miscarriages." Latin America News Dispatch, May 19. https://latindispatch.com/2011/05/19/chilesuspends-use-of-tear-gas-amid-concerns-overmiscarriages/.

Hazari, Mehdi S, Najwa Haykal-Coates, Darrell W Winsett, Q T Krantz, Charly King, Daniel L Costa, Aimen K Farraj. 2011. TRPA1 and sympathetic activation contribute to increased risk of triggered cardiac arrhythmias in hypertensive rats exposed to diesel exhaust." Environmental Health Perspectives, 119(7), 951-957. https://doi.org/10.1289/ehp.1003200.

Himsworth, Harold. Report of the Enquiry into the Medical and Toxicological Aspects of CS (orthochlorobenzylidene malononitrile). Part II. Enquiry into Toxicological Aspects of CS and Its Use for Civil Purposes. (London, UK: Her Majesty's Stationery Office, 1971).

Hox, Valerie, Jeroen A Vanoirbeek, Yeranddy A Alpizar, Sabrina Voedisch, Ina Callebaut, Sonja Bobic, Ali Aharify, Vanessa De Vooght, Laura Van Gerven, Fien Devos, Adrian Liston, Thomas Vorts, Rudi Vennekens, Dominique M A Bullens, Annick De Vries, Peter Hoet, Armin Braun, Jan L Ceuppens, Karel Talavera, Benoit Nemery, Peter W Hellings. 2013. "Crucial role of transient receptor potential ankyrin 1 and mast cells in induction of nonallergic airway hyperreactivity in mice." American Journal of Respiratory and Critical Care $\begin{array}{llll}\text { Medicine } & 187 & \text { (5): } & \text { 486-493. }\end{array}$ https://doi.org/10.1164/rccm.201208-13580c.
Hout, Joseph J, Duvel W White, Anthony R Artino, Joseph J Knapik. 2014. "O-chlorobenzylidene malononitrile (CS riot control agent) associated acute respiratory illnesses in a US Army Basic Combat Training cohort." Military Medicine 179 (7): 793-8. https://doi.org/10.7205/milmed-d13-00514.

Hout, Joseph J, Duvel W White, Michael Stevens, Alex Stubner, Antiony Arino, Joseph Knapik. 2014. "Evaluation of an intervention to reduce tear gas exposures and associated acute respiratory illnesses in a US Army Basic Combat Training cohort." The Open Epidemiology Journal 7 (1): 3745.

http://dx.doi.org/10.2174/18742971201407010 37.

Hu, Howard, Jonathan Fine, Paul Epstein, Karl Kelsey, Preston Reynolds, Bailus Walker. 1989. "Tear Gas-Harassing Agent or Toxic Chemical Weapon?" JAMA 262 (5): 660-663. https://doi.org/10.1001/jama.1989.0343005007 6030.

Ipsos. 2020. "Americans split on the right to protest versus law and order." Ipsos, June 10. https://www.ipsos.com/en-us/news-polls/usatoday-protests-2020.

Koivisto, Ari, Mika Hukkanen, Marja Saarnilehto, Hugh Chapman, Katja Kuokkanen, Hong Wei, Hanna Viisanen, Karl E Akerman, Ken Lindstedt, Antti Pertovaara. 2012. "Inhibiting TRPA1 ion channel reduces loss of cutaneous nerve fiber function in diabetic animals: sustained activation of the TRPA1 channel contributes to the pathogenesis of peripheral diabetic neuropathy." Pharmacological Research 65 (1): 149-158. https://doi.org/10.1016/j.phrs.2011.10.006.

Lai, K K Rebecca, Bill Marsh, Anjali Singhvi. 2020. "Here Are the 100 US Cities Where Protesters Were TearGassed." The New York Times, updated June 18. https://www.nytimes.com/interactive/2020/06 L16/us/george-floyd-protests-police-teargas.html.

Lindsay, Christopher D, Christopher Green, Mike Bird, James TA Jones, James R Riches, Katherine $\mathrm{K}$ McKee, Mark S Sanford, Debra A Wakefield, Christopher M Timperley. 2015. "Potency of irritation by benzylidenemalononitriles in humans correlates with TRPA1 ion channel activation." Royal Society open science, 2(1), 140160. https://doi.org/10.1098/rsos.140160.

Liu, Boyi, Jasmine Escalera, Shrilatha Balakrishna, Lu Fan, Ana I Caceres, Eve Robinson, Aiwei Sui, M C McKay, M A McAlexander, Christina A Herrick, Sven E Jordt. 2013. "TRPA1 controls inflammation and pruritogen responses in allergic contact dermatitis." The FASEB Journal 27 (9): 35493563. https://doi.org/10.1096/fj.13-229948. 
Mccrystal, Laura. 2020. "Philly City Council hears from protesters hit by tear gas and rubber bullets. Now it will consider banning those tactics." The Philadelphia Inquirer, October 7. https://www.inquirer.com/news/philadelphia/t ear-gas-rubber-bullet-ban-philadelphia-policeprotest-20201007.html.

Miranda, Leticia. 2020. "Behind America's tear gas business boom: Low-wage workers and angry neighbors." NBC News, July 13. https://www.nbcnews.com/business/businessnews/behind-america-s-tear-gas-business-boomlow-wage-workers-n1231729.

Mutasa, Tammy. 2020 "'It's pretty traumatizing': Protester hit by SPD flash bang says she nearly died." KOMO News, June 10.

https://komonews.com/news/local/protesterinjured-by-exploding-flash-bang-shares-herstory.

National Research Council. 2014. "Acute Exposure Guideline Levels for Selected Airborne Chemicals: Volume 16." The National Academies Press. https://www.epa.gov/sites/production/files/20 $\underline{14-}$ 11/documents/tear gas final volume 16 2014.p df.

Planned Parenthood North Central States. "Tear Gas and Reproductive Health Study." Planned Parenthood North Central States. Planned Parenthood. Accessed December 292020. https://www.plannedparenthood.org/plannedparenthood-north-central-states/aboutppncs/research/tear-gas-and-reproductivehealth-study.

Public health professionals, infectious diseases professionals, and community stakeholders. "Open letter advocating for an anti-racist public health response to demonstrations against systemic injustice occurring during the COVID-19 pandemic." Open letter. Accessed November 10, 2020.

https://drive.google.com/file/d/1Jyfn4Wd2i6bRi 12ePghMHtX3ys1b7K1A/view.

Rothenberg, Craig, Satyanarayana Achanta, Erik R. Svendsen, Sven-Eric Jordt. 2016. "Tear gas: an epidemiological and mechanistic reassessment." Annals of the New York Academy of Sciences 1378 (1):

96-107. https://doi.org/10.1111/nyas.13141.

Salo, Jackie. 2020. "Protester hit with tear gas by police died of natural causes, autopsy reveals." New York Post, July 12. https://nypost.com/2020/07/12/protesterwho-died-after-being-exposed-to-tear-gassuccumbed-to-natural-causes-autopsy-reveals/.
Schumacher, Tracy. 2020. "We know about injuries to Rochester police Sept. 5. What about injuries to protesters?" Rochester Democrat and Chronicle, September 11. https://www.democratandchronicle.com/story/ news/2020/09/11/how-many-injuriesprotesters-s ept-5-2020-rochesterny/3466996001/.

Selsky, Andrew. 2020. "Lack of study and oversight raises concerns about tear gas." Associated Press, August 6. https://apnews.com/article/charlotte-ap-topnews-police-race-and-ethnicity-healthc814cc7b873ccaf60b95b10e96ecfc12.

Sharma, Ananda K, Dev N Shah, Jeevan K Shrestha, Madhu Thapa, Gauri S Shrestha. 2014. "Ocular injuries in the people's uprising of April 2006 in Kathmandu, Nepal." Nepalese Journal of Ophthalmology 6 (1): 71-79.

https://doi.org/10.3126/nepjoph.v6i1.10775.

Sollom, Richard, Holly Atkinson. 2012. "Weaponizing Tear Gas: Bahrain's Unprecedented Use of Toxic Chemical Agents Against Civilians." Physicians for Human Rights. https://phr.org/wpcontent/uploads/2020/11/Bahrain-TearGasAug2012-small.pdf.

Sveriges Radio. 2012. "Police to use tear gas outdoors." Sveriges Radio, January 29. https://sverigesradio.se/artikel/4935642.

Wang, Zhen, Di Ye, Jing Ye, Menglong Wang, Jianfang Liu, Huimin Jiang, Yao Xu, Jishou Zhang, Jiangbin Chen, and Jun Wan. "The TRPA1 channel in the cardiovascular system: promising features and challenges." Frontiers in pharmacology 10 (2019): 1253.

https://dx.doi.org/10.3389\%2Ffphar.2019.0125 3.

Wani, Mohd Lateef, Ab Gani Ahangar, Gh Nabu Lone, Shyam Singh, Abdul Majeed Dar, Mohn Akbar Bhat, Hakeem Zubair Ashraf, Ifat Irshad. 2011. "Vascular injuries caused by tear gas shells: surgical challenge and outcome." Iranian Journal of Medical Sciences $\quad 36 \quad$ (1): $14-17$. https://www.ncbi.nlm.nih.gov/pmc/articles/PM C3559117/.

Watson, Karen, Richard Rycroft. 2005. "Unintended cutaneous reactions to CS spray." Contact Dermatitis $53 \quad$ (1): $\quad 9-13$. https://doi.org/10.1111/i.01051873.2005.00585.x.

Wetsman, Nicole. 2020. “There isn't enough research to know if tear gas causes early periods." The Verge, June 22. https://www.theverge.com/2020/6/22/212951 59/tear-gas-menstural-cycle-miscarriage-periodprotests. 
Wilkinson, Katherine. 2020. "Tear gas during the COVID-19 crisis can be deadly — ban it." The Hill, October 21. https://thehill.com/opinion/healthcare/521994tear-gas-during-the-covid-19-crisis-can-bedeadly-ban-it

Lauren Wagner is a doctoral student of Neuroscience at the University of California, Los Angeles, where she uses fMRI, and behavior, and genetics to understand the neural bases of language development. She is currently the Secretary of the Science Policy Group at UCLA and enjoys researching issues in science policy/diplomacy and linguistic equity within the global scientific sphere. Lauren received her bachelor's degrees in Neuroscience and Linguistics from the University of Texas at Austin.

Zoe Guttman is currently completing the Interdepartmental PhD Program for Neuroscience at the University of California, Los Angeles. Her research stands at the intersection of cognitive neuroscience, behavioral economics, and addiction to understand decision-making under conditions of risk and uncertainty. Zoe holds a BS in Neural Science and Psychology from New York University. She is also the co-founder and president of the Science Policy Group at UCLA.

Yuki Hebner is a student in the Gene Regulation, Epigenomics, and Transcriptomics PhD program at the University of California, Los Angeles. She studies chromatin remodeling during human corticogenesis to understand the epigenetic drivers of neuropsychiatric diseases. Previously, she studied histone biology at Wesleyan University. She is the internal vice president of the Science Policy Group at UCLA.

Conner S. Philson is a Ph.D. Student in Ecology and Evolutionary Biology at UCLA studying the evolution and consequences of social behavior using the yellow-bellied marmot population at the Rocky Mountain Biological Laboratory (RMBL) in Colorado. His science policy work focuses on combating climate change, environmental degradation, and loss of biodiversity by communicating science to voters and policy makers. He plans to pursue a career in science policy/diplomacy. 